\title{
Immunological effects of occupational exposure to lead (Review)
}

\author{
CONCETTINA FENGA ${ }^{1}$, SILVIA GANGEMI ${ }^{1}$, VALENTINA DI SALVATORE ${ }^{2}$, \\ LUCA FALZONE $^{2}$ and MASSIMO LIBRA ${ }^{2}$
}

\author{
${ }^{1}$ Department of Biomedical, Odontoiatric, Morphological and Functional Images, Section of Occupational Medicine, \\ 'Policlinico G. Martino' Hospital, University of Messina, I-98125 Messina; ${ }^{2}$ Department of Biomedical and \\ Biotechnological Sciences, Laboratory of Translational Oncology and Functional Genomics, Section of General \\ and Clinical Pathology and Oncology, University of Catania, I-95124 Catania, Italy
}

Received January 4, 2017; Accepted February 23, 2017

DOI: $10.3892 / \mathrm{mmr} .2017 .6381$

\begin{abstract}
It is well-known that occupational and environmental exposure to several factors, including benzene, heavy metals, chemicals and mineral fibers, is associated with the risk of developing a great number of diseases. Numerous studies have been carried out in order to investigate the mechanisms of toxicity of these substances, with particular regard to the possible toxic effects on the immune system. However, little is known about the influence of heavy metals, such as lead, on the immune system in human populations. Lead is a heavy metal still used in many industrial activities. Human exposure to lead can induce various biological effects depending upon the level and duration of exposure, such as toxic effects on haematological, cardiovascular, nervous and reproductive systems. Several studies demonstrated that exposure to lead is associated to toxic effects also on the immune system, thus increasing the incidence of allergy, infectious disease, autoimmunity or cancer. However, the effects of lead exposure on the human immune system are not conclusive, mostly in occupationally exposed subjects; nevertheless some immunotoxic abnormalities induced by lead have been suggested. In particular, in vivo, in vitro and ex vivo lead is able to improve T helper 2 (Th2) cell development affecting Th1 cell proliferation. Further studies are required to better understand the mechanisms of lead immunotoxicity and the ability of lead to affect preferentially one type of immune response.
\end{abstract}

\section{Contents}

1. Introduction

2. Mechanisms of lead-induced toxicity

Correspondence to: Dr Silvia Gangemi, Department of Biomedical, Odontoiatric, Morphological and Functional Images, Section of Occupational Medicine, 'Policlinico G. Martino' Hospital, University of Messina, Via Consolare Valeria 1, I-98125 Messina, Italy E-mail: silviagangemi@hotmail.com

Key words: occupational exposure, lead, heavy metals
3. Lead exposure and Th1 type cytokines

4. Lead exposure and Th2 type cytokines

5. Th17 type cytokines and Treg cells

6. Conclusion

\section{Introduction}

It is well-known that occupational and environmental exposure to several factors, including benzene, heavy metals, biological substances and chemicals, may induce adverse effects on human health by promoting the develop of specific disorders and diseases, such as haematological, immunological, cardiovascular, reproductive, neurodegenerative diseases and cancer (1-8). Epidemiological and experimental studies have been carried out in order to investigate the mechanisms of toxicity of these substances, with particular regard to the possible toxic effects on the immune system (9-13). However, little is known about the influence of heavy metals, such as lead, on the immune system in human populations (14).

Lead is a heavy metal which has been widely used in various industrial and domestic settings, due to its physical and chemical properties. Lead is found in pottery, pipes, boat building, manufacture of windows, arms industry, pigments and printing of books. Although its use in several settings has been restricted due to its toxicity to humans, lead and its compounds are still used in many industrial activities such as in production of paints, storage batteries, ceramics, in manufacturing of motor and electric vehicles, building and construction industries, electronic technologies, smelters and welding (15). It is also present in gasoline, in drinking water and in tobacco smoke (16).

In developing countries, many workers continue to be exposed to toxic effects of lead due to lack of knowledge on its safe handling; certain groups of individuals in the general population are still at risk from lead exposure, including pregnant women and their foetuses (17). In this regard, occupational and environmental contamination and exposure to lead still represent a serious issue for human health.

Inhalation and ingestion represent the main routes of exposure, especially for occupationally exposed subject. After absorption, lead distributes and accumulates in blood, bones 
and soft tissues, especially liver and kidney. Therefore, these organs are particularly sensitive to lead toxicity (18).

Human exposure to lead can induce various biological effects depending upon the level and duration of exposure, such as toxic effects on haematological, cardiovascular, nervous and reproductive systems (19-24). Although the occurrence of adverse health effects has been largely reduced, the incidence of subclinical effects of chronic exposure to low-doses of lead has been increasing (16).

Furthermore, lead has been classified as possible human carcinogen (group 2B) (25) and its inorganic compounds as probable human carcinogens (group 2A) (26) by the International Agency for Research on Cancer (IARC). Lead exposure has been associated with increased risk of lung, stomach and bladder cancer in diverse human populations (27-31). The proposed mechanisms of lead carcinogenicity include mitogenesis, alterations in gene transcription, oxidative damage and several indirect genotoxicity mechanisms $(32,33)$. Several studies demonstrated that lead is capable of inducing genotoxic and mutagenic effects, but the results on these topics are still contradictory $(34,35)$. Furthermore, lead can cause epigenetic modifications $(36,37)$; however, the role of environmental exposure in epigenetic alterations remains to be fully investigated as, it may be difficult to identify the cause-effect links among environmental factors, epigenetic changes and diseases (38).

In addition, a number of experimental studies have shown that acute and chronic exposure to lead may influence immune responses, even at subclinical doses in animals and also in vitro systems, which may increase the incidence of allergy, infectious disease, autoimmunity or cancer $(39,40)$. In vitro, lead exposure enhances both B cell and T cell production and major histocompatibility complex (MHC) activity (41). In vivo and ex vivo animal studies and studies in vitro show that lead can activate responses mediated by T helper 2 (Th2) cells and suppress the production of Th1 cells (42). Th cells represent two polarized forms of the $\mathrm{CD} 4^{+}$Th cell-mediated specific immune responses, helper cells can be divided into distinct subsets, including Th1, Th2, Th17 and T regulatory (Treg) cells (43). However, the effects of lead exposure on the human immune system are not conclusive, mostly in occupationally exposed subjects; nevertheless some immunotoxic abnormalities induced by lead have been suggested $(44,45)$. Probably the immunotoxic effects of lead vary according to form of lead, route, dose, time of exposure, and host age and genetic susceptibility (46-48).

\section{Mechanisms of lead-induced toxicity}

Recentepidemiological studies have demonstrated thatexposure to lead is correlated to several diseases such as blood pressure increased levels, kidney disease, neurodegenerative disease and cognitive disorders (46,49-52), which are all associated to oxidative stress. Oxidative stress is known as an imbalance between the production of reactive oxygen species (ROS) and antioxidants in favour of free radicals (ROS) $(53,54)$. Several studies reported that lead can induce oxidative stress in occupationally exposed workers as well as in general population, by two different mechanisms, the first is the pro-oxidative effect of $\delta$-aminolevulinic acid dehydratase ( $\delta$-ALAD) and the second is connected with the direct effect of lead on the lipid composition of cellular membranes $(55,56)$. The inhibition of $\delta$-ALAD by lead accounts for the accumulation of its substrate $\delta$-ALA, that can be rapidly oxidized to generate free radicals as superoxide ion $\left(\mathrm{O}_{2}^{-*}\right)$, hydroxyl radical $(\cdot \mathrm{OH})$, and hydrogen peroxide $\left(\mathrm{H}_{2} \mathrm{O}_{2}\right)$. Lead has also the capacity of stimulating ferrous ion initiated membrane lipid peroxidation (56).

The decrease of the levels of glutathione (GSH) and protein bound sulfhydryl groups and the changes in the activity of various antioxidant enzymes indicative of lipid peroxidation have been implicated in lead-induced oxidative tissue damage (57). Lead is known to have toxic effects on membrane structure and functions by altering changes in the fatty acid composition of membrane which are more susceptible to lipid peroxidation. This effect is particular evident on erythrocyte membranes because erythrocytes have a high affinity for lead and are more vulnerable to oxidative damage than many other cells (55).

Besides, lead is able to dysregulate the antioxidant defenses, including the antioxidant enzymes and the non-enzymatic antioxidants, such as uric acid (58).

Another mechanism of lead-induced toxicity implicates the immune system. Epidemiological and experimental studies suggest that lead can influence levels of immunoglobulins, alterations in the numbers of lymphocytes, peripheral blood mononuclear cells (PBMCs) and macrophages, impaired responses to mitogens and depression of neutrophil functions $(15,59,60)$.

In vitro studies demonstrated that the treatment of macrophages with lead induces the disregulation of the production of proinflammatory cytokines, such as tumor necrosis factor- $\alpha$ (TNF- $\alpha)$, interleukin- $1 \alpha$ (IL-1 $\alpha)$ and IL-6, and promote the synthesis of Th1 cytokines [interferon (IFN)- $\gamma$ and IL-2] $(42,61)$.

$\mathrm{CD}^{+}$Th cell function is mostly sensitive to the immunotoxic effects of lead. Several studies have demonstrated that lead is able to improve Th2 cell development and affect Th1 cell proliferation $(42,62)$. The differential influence of lead on Th1 vs. Th2 activation may be at the level of the antigen-presenting cells (APCs) or the T cell itself. Lead may induce the differential activation of Th subsets by modulating the activity of APC through the modulation of antigen density, a change in the expression of costimulatory molecules on APC, and/or a change in membrane fluidity of the APC (42).

On the contrary, little is known about the possible associations between lead exposure and the function of Th17 and Treg cells.

Besides, lead exerts proinflammatory properties, as reported in studies conducted particularly on occupationally exposed populations $(15,46,63)$.

It has been suggested that lead can also influence the production and the activity of other cells, such as granulocytes and monocytes. The functional activities of these cells are actually regulated by a number of cytokines and by nitric oxide (NO), having both a central role in innate and adaptive immune responses. This hypothesis suggests that lead can influence the cellular and humoral immune response and decrease host resistance (64). However, the exact mechanisms of lead interactions with the immune system in humans still remain unclear (65). 


\section{Lead exposure and Th1 type cytokines}

Th1-mediated responses promote cellular cytotoxic immunity by producing IFN- $\gamma$, IL-2 and TNF- $\alpha$, which have effect on the production of opsonizing and complement-fixing antibodies by $\mathrm{B}$ cells, activation of macrophages, cell cytotoxicity, and induction of cell-mediated immunity (CMI). Th1-dominated immune responses predominantly produce a phagocyte-dependent inflammation $(43,66)$.

Production of IFN- $\gamma$ is frequently used to assess Th1 responses. Lead exposure has been demonstrated to inhibit IFN- $\gamma$ production in vivo, in vitro and ex vivo. Heo et al examined lead effects on the modifications of the Th-derived cytokines IL-4 and IFN- $\gamma$ in vitro, ex vivo and in vivo. Their results demonstrated that in vitro, in vivo and ex vivo lead inhibits IFN- $\gamma$ production from a Th1 clone and enhance IL-4 production from a Th 2 clone. The plasma IFN- $\gamma$ levels in mice exposed to lead were significantly lower, on the contrary, plasma IL-4 and IgE levels were elevated, suggesting a preferential activation of Th2 cells and the occurrence of autoimmune responses. Also, lead effects were investigated on expression of IFN- $\gamma$ mRNA, secretion of IFN- $\gamma$ protein, proteosomal processing, and kinetics of IFN- $\gamma$ protein biosynthesis. The results of this study confirmed that in vitro IFN- $\gamma$ biosynthesis is suppressed by lead exposure of Th1 cells at a post-transcriptional stage, indicating that lead inhibitory role is at the translational stage of IFN- $\gamma$ biosynthesis (67).

In a recent study conducted on three population groups with different period of exposure, the authors highlighted significant higher levels of IFN- $\gamma$, IL-2 and IL-12 in workers chronically exposed to lead ( $13 \pm 10$ years) compared to workers exposed to lead for 36 to 44 days and to a group of not exposed subjects (68).

It has been demonstrated that lead causes a significant increase of TNF- $\alpha$ production, both in vitro and in vivo studies $(61,69,70)$. In particular, lead induces an increase of TNF- $\alpha$ at low-doses and a decrease at higher-doses, as demonstrated in human peripheral blood mononuclear cells, in rats, and in exposed workers compared to controls (71).

To evaluate the effects of lead exposure on the activity of TNF- $\alpha$, rabbit pulmonary macrophages were exposed in vitro to particulate lead oxide $(\mathrm{PbO})$ for periods of up to $72 \mathrm{~h}$ and then assayed for the activity of TNF- $\alpha$ released after stimulation with lipopolysaccharide (LPS). The levels of TNF- $\alpha$ obtained from $\mathrm{PbO}$-treated cells were decreased in a dose-dependent manner as compared with metal-free control cells for each time-point examined. In addition, incubation of cell-free TNF- $\alpha$ with $\mathrm{PbO}$ resulted in a decrease of macrophage cytotoxicity directed against TNF- $\alpha$-sensitive tumor target cells (72).

As regard the influence of lead on the immune system in humans, Yücesoy et al evaluated the levels of serum IL-1 $\beta$, IL-2, TNF- $\alpha$ and IFN- $\gamma$ in a group of workers occupationally exposed to lead and cadmium. The results reported that chronic lead and cadmium exposure in humans resulted in significant reduction of the serum IL-1 $\beta$ levels, but did not influence IL-2 and TNF- $\alpha$ levels. A decrease in IFN- $\gamma$ levels was found in lead exposed group (46).

A great number of studies have shown that lead exposure can produce higher levels of the inflammatory cytokines, such TNF- $\alpha$, IL- 6 and IL-1 $\beta$ both in vitro and in vivo $(15,73,74)$. In particular, Liu et al demonstrated that antioxidant molecules could inhibit the lead-induced production of several proinflammatory cytokines, mainly IL-1 $\beta$, TNF- $\alpha$ and IL- 6 . The synthesis of proinflammatory cytokines involves the activation of mitogen-activated protein kinases (MAPKs) and nuclear factor- $\kappa \mathrm{B}(\mathrm{NF}-\kappa \mathrm{B})(75)$.

\section{Lead exposure and Th2 type cytokines}

Th2-mediated responses are responsible for humoral immunity and Th2 cells produce IL-4, IL-5, IL-6, IL-9, IL-10 and IL-13, which induce strong antibody responses, including IgE, eosinophil differentiation and activation, but inhibit several functions of phagocytic cells, thus promoting a form of phagocyte-independent inflammation (43).

Epidemiological and experimental studies have been conducted in order to evaluate the effects of lead on Th2 cytokines. It has been reported that exposure to lead promotes IL-4 production and inhibits IFN- $\gamma$ synthesis in wild-type BALB/c mice, and enhances delayed-type hypersensitivity (DTH) responses in IFN- $\gamma$ deficient mice (76).

Iavicoli et al investigated the effects of a broad range of blood lead concentrations in mice, obtained over an entire lifespan (from conception to sacrifice) on serum levels of two type 1 cytokines (IL-2 and INF- $\gamma$ ) and one type 2 cytokine (IL-4). At higher dietary Pb levels (40 and 400 ppm), a significant increase in IL-4 production was associated with a profound decrease in INF- $\gamma$ and IL-2 synthesis. At the lowest $\mathrm{Pb}$ diet level $(0.02 \mathrm{ppm})$, which resulted in a blood lead level of $0.8 \mu \mathrm{g} / \mathrm{dl}$, which is below background $(2-3 \mu \mathrm{g} / \mathrm{dl})$ values in humans, increases in INF- $\gamma$ and IL- 2 production along with a significant decrease in IL-4 production were observed. These findings provided evidence of a different trend of lead-induced cytokines availability depending on different blood lead concentration. As blood lead level increases, there is a skewing toward Th2, while Th1 production is promoted at lower blood lead values (48).

In another study, Valentino et al assessed plasma levels of nitrites and nitrates (NOx), IL-2, IL-4, IL-6, IL-10, TNF- $\alpha$ and INF- $\gamma$ in healthy workers with very low and low lead exposure compared to a control group of not exposed workers. Subjects exposed to low levels of lead showed significantly higher plasma levels of IL-10 and TNF- $\alpha$, compared to non-exposed workers. The significant positive correlation between lead and IL-10 levels seems to suggest a dose-dependent mechanism. The study suggests that cytokine balance is modified with an increase of plasma TNF- $\alpha$ and IL-10 levels. Interestingly, it is well-documented that these two cytokines have different biological activity. So the authors hypothesised that the system of immunophlogosis of exposed workers in response to low lead levels shows an increase of proinflammatory cytokines, such as TNF- $\alpha$, with a consequent increase of other cytokines, such as IL-10, considered a T cell cross-regulatory factor (71).

Hsiao et al assessed whole blood $\mathrm{Pb}$ levels and changes in levels of key Th1 and Th2 cytokines in school children from Taiwanese communities with different levels of lead exposure depending upon their living area (urban area with new homes, urban area with old homes, rural site with old homes and area located near an oil refinery) and the absence of respiratory and allergic disease. Refinery children had significantly increased 
$\mathrm{Pb}$ levels and children with allergies had serum Th2 cytokine levels (IL-4 and IL-5) significantly higher and Th1 cytokine levels (IFN- $\gamma$ and IL-12) significantly lower than their healthy counterparts. Healthy refinery students did not show altered Th1 or Th2 cytokine levels. The authors concluded that substantially increased whole blood $\mathrm{Pb}$ levels may induce Th cell dysregulation and affect the production of key Th1 and Th2 cytokines, which could also contribute to development of respiratory allergic disorders (40).

Recently, it has been hypothesized that lead can influence count and function of red blood cells (RBCs), platelet (PLT) and leukocyte (WBC) indices by acting on immune system. In a study on 37 males occupationally exposed to lead for a short period of time (36-44 days), the authors evaluated peripheral blood morphology and levels of several cytokines, including IL-7 and IL-9, granulocyte colony-stimulating factor (G-CSF), granulocyte-macrophage colony-stimulating factor (GM-CSF), hepatocyte growth factor (HGF), stem cell factor (SCF), platelet-derived growth factor (PDGF), and platelet endothelial cell adhesion molecule-1 (PECAM-1). The results of the study highlighted decreased haemoglobin level, probably due to the lead induced inhibition of ALAD, and increased counts of WBC and PLT. The measurement of cytokines showed a significant decrease in IL-7 levels, while the level of IL-9 did not change significantly. According to the authors, a short-term lead exposure could be associated to a decrease in levels of cytokines related to haematopoiesis (58).

\section{Th17 type cytokines and Treg cells}

Th17 cells are responsible for host defence against infections by bacteria and fungi and in tissue inflammation. Th17 cells produce IL-17 and IL-22, which activate mononuclear phagocytes and also recruit neutrophils, thus inducing epithelial antimicrobial responses (66). Treg cells were originally identified as $\mathrm{CD} 4{ }^{+} \mathrm{CD} 25^{+}$and are able to induce immune-suppressive responses (77). Unfortunately, there are few studies on the effects of lead on these Th cells and their results are not conclusive. As regard IL-17, Dobrakowski et al demonstrated that short-term exposure to lead did not influence IL-17 levels, while increased levels of IL-17 were reported in workers chronically exposed to lead (68).

In vivo, $\mathrm{Foxp}^{+}$Tregs were increased in both the thymus and peripheral lymphoid organs of rats exposed to lead, although conventional $\mathrm{CD}^{+}{ }^{+} \mathrm{T}$ cells were decreased. The mechanism by which lead exposure can induce Treg number increase remains unclear. It has been demonstrated that lead enhances rather than inhibits suppressor cell activity (78). In contrast, this study suggest the hypothesis that lead exposure can lead to immunosuppression by upregulating production of Tregs.

\section{Conclusion}

It is well-established that exposure to lead can promote the development of several diseases and disorders through different mechanisms of toxicity. The hypothesis that the immune system represents a critical target for lead-induced toxicity has been suggested by recent epidemiological and experimental studies. In particular, lead can affect both cellular and humoral immune response by altering Th cell function and increasing susceptibility to the development of autoimmunity and hypersensitivity (44). In the context of hypersensitivity, the use of cyclophosphamide may affect the immune response by reducing the expression levels of several cytokines as occurred in our previous in vivo experience $(79,80)$. A great number of epidemiological and experimental studies are available, but results are often contradictory because of some limitations, such as the presence of possible confounding factors, the size of the samples, the dose and time of exposure to lead, and the use of safety measurement in occupational environment. Furthermore, few studies evaluated the effects of lead exposure on subjects occupationally exposed to low-dose of lead. Further studies are needed in order to investigate the mechanisms of lead immunotoxicity and the ability of lead to affect preferentially one type of immune response.

\section{References}

1. Rapisarda V, Valentino M, Ravalli P, Fenga C and Duscio D: Occupational brucellosis in slaughtering of sheep and goats: study of five cases from a municipal abattoir in south-eastern Sicily. Med Lav 96: 134-141, 2005 (In Italian).

2. Fenga C, Catania C, Di Nola C, Cacciola A, Germanò D and Costa C: Air pollution in urban areas as a risk factor for health in the general population and in workers. Environmental and biologic monitoring of 1-3 butadiene. G Ital Med Lav Ergon 29 (Suppl 3): 861-863, 2007 (In Italian).

3. Fenga C: Occupational exposure and risk of breast cancer. Biomed Rep 4: 282-292, 2016.

4. Costa C, Ozcagli E, Gangemi S, Schembri F, Giambò F, Androutsopoulos V, Tsatsakis A and Fenga C: Molecular biomarkers of oxidative stress and role of dietary factors in gasoline station attendants. Food Chem Toxicol 90: 30-35, 2016.

5. Miozzi E, Rapisarda V, Marconi A, Costa C, Polito I, Spandidos DA, Libra $\mathrm{M}$ and Fenga $\mathrm{C}$ : Fluoro-edenite and carbon nanotubes: the health impact of 'asbestos-like' fibres. Exp Ther Med 11: 21-27, 2016

6. Gangemi S, Gofita E, Costa C, Teodoro M, Briguglio G, Nikitovic D, Tzanakakis G, Tsatsakis AM, Wilks MF, Spandidos DA, et al: Occupational and environmental exposure to pesticides and cytokine pathways in chronic diseases (Review). Int J Mol Med 38: 1012-1020, 2016.

7. Guarneri F, Costa C, Cannavò SP, Catania S, Bua GD, Fenga C and Dugo G: Release of nickel and chromium in common foods during cooking in 18/10 (grade 316) stainless steel pots. Contact Dermat 76: 40-48, 2017.

8. Ledda C, Loreto C, Zammit C, Marconi A, Fago L, Matera S, Costanzo V, Fuccio Sanzà G, Palmucci S, Ferrante M, et al: Non infective occupational risk factors for hepatocellular carcinoma: a review. Mol Med Rep 15: 511-533, 2017.

9. Fenga C, Cacciola A, Di Nola C, Calimeri S, Lo Giudice D, Pugliese M, Niutta PP and Martino LB: Serologic investigation of the prevalence of Chlamydophila psittaci in occupationally-exposed subjects in eastern Sicily. Ann Agric Environ Med 14: 93-96, 2007.

10. Fenga C, Cacciola A, Rapisarda V, Spatari G, Calimeri S, Minciullo PL, Di Pasquale G and Gangemi S: Chlamydophila psittaci seropositivity and serum levels of soluble intercellular adhesion molecule-1 in farmers. Ann Agric Environ Med 15: 277-280, 2008.

11. Costa C, Rapisarda V, Catania S, Di Nola C, Ledda C and Fenga C: Cytokine patterns in greenhouse workers occupationally exposed to $\alpha$-cypermethrin: an observational study. Environ Toxicol Pharmacol 36: 796-800, 2013.

12. Fenga C, Gangemi S, Catania S, De Luca A and Costa C: IL-17 and IL-22 serum levels in greenhouse workers exposed to pesticides. Inflamm Res 63: 895-897, 2014.

13. Ledda C, Loreto C, Matera S, Massimino N, Cannizzaro E, Musumeci A, Migliore M, Fenga C, Pomara C and Rapisarda V: Early effects of fluoro-edenite: correlation between IL-18 serum levels and pleural and parenchymal abnormalities. Future Oncol 12: 59-62, 2016. 
14. Hengstler JG, Bolm-Audorff U, Faldum A, Janssen K, Reifenrath M, Götte W, Jung D, Mayer-Popken O, Fuchs J, Gebhard S, et al: Occupational exposure to heavy metals: DNA damage induction and DNA repair inhibition prove co-exposures to cadmium, cobalt and lead as more dangerous than hitherto expected. Carcinogenesis 24: 63-73, 2003.

15. Mishra KP, Singh VK, Rani R, Yadav VS, Chandran V, Srivastava SP and Seth PK: Effect of lead exposure on the immune response of some occupationally exposed individuals. Toxicology 188: 251-259, 2003.

16. García-Lestón J, Roma-Torres J, Vilares M, Pinto R, Cunha LM Prista J, Teixeira JP, Mayan O, Pásaro E, Méndez J, et al: Biomonitoring of a population of Portuguese workers exposed to lead. Mutat Res 721: 81-88, 2011.

17. Weizsaecker K: Lead toxicity during pregnancy. In: Prim Care Update Ob Gyns. Vol 10. Elsevier, pp304-309, 2003.

18. Alya A, Ines DB, Montassar L, Najoua G and Saloua F: Oxidative stress, biochemical alterations, and hyperlipidemia in female rats induced by lead chronic toxicity during puberty and post puberty periods. Iran J Basic Med Sci 18: 1034-1043, 2015.

19. Tang $\mathrm{N}$ and Zhu ZQ: Adverse reproductive effects in female workers of lead battery plants. Int J Occup Med Environ Health 16: 359-361, 2003

20. Navas-Acien A, Guallar E, Silbergeld EK and Rothenberg SJ: Lead exposure and cardiovascular disease - a systematic review. Environ Health Perspect 115: 472-482, 2007.

21. Sanders T, Liu Y, Buchner V and Tchounwou PB: Neurotoxic effects and biomarkers of lead exposure: a review. Rev Environ Health 24: 15-45, 2009.

22. Nigra AE, Ruiz-Hernandez A, Redon J, Navas-Acien A and Tellez-Plaza M: Environmental metals and cardiovascular disease in sdults: a systematic review beyond lead and cadmium. Curr Environ Health Rep 3: 416-433, 2016.

23. Bertke SJ, Lehman EJ, Wurzelbacher SJ and Hein MJ: Mortality of lead smelter workers: a follow-up study with exposure assessment. Am J Ind Med 59: 979-986, 2016.

24. Rzymski P, Tomczyk K, Rzymski P, Poniedziałek B, Opala T and Wilczak M: Impact of heavy metals on the female reproductive system. Ann Agric Environ Med 22: 259-264, 2015.

25. No authors listed: Overall evaluations of carcinogenicity: an updating of IARC monographs volumes 1 to 42. IARC Monogr Eval Carcinog Risks Hum (Suppl) 7: 1-440, 1987.

26. IARC Working Group on the Evaluation of Carcinogenic Risks to Humans: Inorganic and organic lead compounds. IARC Monogr Eval Carcinog Risks Hum 87: 1-471, 2006.

27. Steenland K and Boffetta P: Lead and cancer in humans: where are we now? Am J Ind Med 38: 295-299, 2000.

28. Rousseau MC, Parent ME, Nadon L, Latreille B and Siemiatycki J: Occupational exposure to lead compounds and risk of cancer among men: a population-based case-control study. Am J Epidemiol 166: 1005-1014, 2007.

29. Golabek T, Darewicz B, Borawska M, Markiewicz R, Socha K and Kudelski J: Lead concentration in the bladder tissue and blood of patients with bladder cancer. Scand J Urol Nephrol 43 467-470, 2009

30. Wynant W, Siemiatycki J, Parent MÉ and Rousseau MC: Occupational exposure to lead and lung cancer: results from two case-control studies in Montreal, Canada. Occup Environ Med 70: 164-170, 2013.

31. McElvenny DM, Miller BG, MacCalman LA, Sleeuwenhoek A, van Tongeren M, Shepherd K, Darnton AJ and Cherrie JW: Mortality of a cohort of workers in Great Britain with blood lead measurements. Occup Environ Med 72: 625-632, 2015.

32. Minozzo R, Deimling LI and Santos-Mello R: Cytokinesis-blocked micronucleus cytome and comet assays in peripheral blood lymphocytes of workers exposed to lead considering folate and vitamin B12 status. Mutat Res 697: $24-32,2010$

33. Dobrakowski M, Pawlas N, Kasperczyk A, Kozłowska A, Olewińska E, Machoń-Grecka A and Kasperczyk S: Oxidative DNA damage and oxidative stress in lead-exposed workers. Hum Exp Toxicol: Sep 5, 2016 (Epub ahead of print).

34. García-Lestón J, Méndez J, Pásaro E and Laffon B: Genotoxic effects of lead: an updated review. Environ Int 36: 623-636, 2010

35. Li C, Yang X, Xu M, Zhang J and Sun N: Epigenetic marker (LINE-1 promoter) methylation level was associated with occupational lead exposure. Clin Toxicol (Phila) 51: 225-229, 2013.

36. Sen A, Heredia N, Senut MC, Land S, Hollocher K, Lu X, Dereski MO and Ruden DM: Multigenerational epigenetic inheritance in humans: DNA methylation changes associated with maternal exposure to lead can be transmitted to the grandchildren. Sci Rep 5: 14466, 2015.
37. Eid A and Zawia N: Consequences of lead exposure, and it's emerging role as an epigenetic modifier in the aging brain. Neurotoxicology 56: 254-261, 2016.

38. Fenga $\mathrm{C}$, Gangemi $\mathrm{S}$ and Costa $\mathrm{C}$ : Benzene exposure is associated with epigenetic changes (Review). Mol Med Rep 13 3401-3405, 2016

39. Dietert RR, Lee JE, Hussain I and Piepenbrink M: Developmental immunotoxicology of lead (Review). Toxicol Appl Pharmacol 198: 86-94, 2004

40. Hsiao CL, Wu KH and Wan KS: Effects of environmental lead exposure on T-helper cell-specific cytokines in children. J Immunotoxicol 8: 284-287, 2011

41. Kasten-Jolly J, Heo Y and Lawrence DA: Impact of developmental lead exposure on splenic factors. Toxicol Appl Pharmacol 247: 105-115, 2010.

42. Heo Y, Parsons PJ and Lawrence DA: Lead differentially modifies cytokine production in vitro and in vivo. Toxicol Appl Pharmacol 138: 149-157, 1996.

43. Romagnani S: T-cell subsets (Th1 versus Th2). Ann Allergy Asthma Immunol 85: 9-18, 2000.

44. Mishra KP: Lead exposure and its impact on immune system: a review. Toxicol In Vitro 23: 969-972, 2009.

45. Niu Y, Yu W, Fang S, Liu S, Yang Z, Liu W, Chen S, Yang L, Li B and Li Y: Lead poisoning influences TCR-related gene expression patterns in peripheral blood T-lymphocytes of exposed workers. J Immunotoxicol 12: 92-97, 2015.

46. Yücesoy B, Turhan A, Ure M, Imir T and Karakaya A: Effects of occupational lead and cadmium exposure on some immunoregulatory cytokine levels in man. Toxicology 123: 143-147, 1997.

47. Mishra KP, Chauhan UK and Naik S: Effect of lead exposure on serum immunoglobulins and reactive nitrogen and oxygen intermediate. Hum Exp Toxicol 25: 661-665, 2006.

48. Iavicoli I, Carelli G, Stanek EJ III, Castellino N and Calabrese EJ Below background levels of blood lead impact cytokine levels in male and female mice. Toxicol Appl Pharmacol 210: 94-99, 2006.

49. Fenga C, Cacciola A, Martino LB, Calderaro SR, Di Nola C, Verzera A, Trimarchi G and Germanò D: Relationship of blood lead levels to blood pressure in exhaust battery storage workers Ind Health 44: 304-309, 2006.

50. Mason LH, Harp JP and Han DY: Pb neurotoxicity: neuropsychological effects of lead toxicity. Biomed Res Int 2014: 840547, 2014

51. Rapisarda V, Ledda C, Ferrante M, Fiore M, Cocuzza S, Bracci $\mathrm{M}$ and Fenga $\mathrm{C}$ : Blood pressure and occupational exposure to noise and lead $(\mathrm{Pb})$ : a cross-sectional study. Toxicol Ind Health 32: 1729-1736, 2016.

52. Fenga C, Gangemi S, Alibrandi A, Costa C and Micali E: Relationship between lead exposure and mild cognitive impairment. J Prev Med Hyg 57: E205-E210, 2016

53. Costa C, Gangemi S, Giambò F, Rapisarda V, Caccamo D and Fenga C: Oxidative stress biomarkers and paraoxonase 1 polymorphism frequency in farmers occupationally exposed to pesticides. Mol Med Rep 12: 6353-6357, 2015.

54. Fenga C, Gangemi S, Giambò F, Tsitsimpikou C, Golokhvast K, Tsatsakis A and Costa C: Low-dose occupational exposure to benzene and signal transduction pathways involved in the regulation of cellular response to oxidative stress. Life Sci 147: 67-70, 2016.

55. Lopes AC, Peixe TS, Mesas AE and Paoliello MM: Lead exposure and oxidative stress: a systematic review. Rev Environ Contam Toxicol 236: 193-238, 2016.

56. Ahamed M and Siddiqui MK: Low level lead exposure and oxidative stress: current opinions (Review). Clin Chim Acta 383: 57-64, 2007.

57. Jiao X, Yang K, An Y, Teng X and Teng X: Alleviation of lead-induced oxidative stress and immune damage by selenium in chicken bursa of Fabricius. Environ Sci Pollut Res Int: Jan 23, 2017 (Epub ahead of print).

58. Dobrakowski M, Boroń M, Czuba ZP, Birkner E, Chwalba A, Hudziec E and Kasperczyk S: Blood morphology and the levels of selected cytokines related to hematopoiesis in occupational short-term exposure to lead. Toxicol Appl Pharmacol 305: 111-117, 2016.

59. Undeğer U and Başaran N: Effects of lead on neutrophil functions in occupationally exposed workers. Environ Toxicol Pharmacol 5: 113-117, 1998.

60. Başaran N and Undeğer U: Effects of lead on immune parameters in occupationally exposed workers. Am J Ind Med 38: $349-354,2000$ 
61. Krocova Z, Macela A, Kroca M and Hernychova L: The immunomodulatory effect(s) of lead and cadmium on the cells of immune system in vitro. Toxicol In Vitro 14: 33-40, 2000.

62. Gao D, Mondal TK and Lawrence DA: Lead effects on development and function of bone marrow-derived dendritic cells promote Th2 immune responses. Toxicol Appl Pharmacol 222: 69-79, 2007.

63. Boscolo P, Di Gioacchino M, Sabbioni E, Di Giacomo F, Reale M, Volpe AR, Di Sciascio MB, Conti P and Giuliano G: Lymphocyte subpopulations, cytokines and trace elements in asymptomatic atopic women exposed to an urban environment. Life Sci 67: 1119-1126, 2000.

64. McCabe MJ Jr, Singh KP and Reiners JJ Jr: Lead intoxication impairs the generation of a delayed type hypersensitivity response. Toxicology 139: 255-264, 1999.

65. García-Lestón J, Roma-Torres J, Mayan O, Schroecksnadel S, Fuchs D, Moreira AO, Pásaro E, Méndez J, Teixeira JP and Laffon B: Assessment of immunotoxicity parameters in individuals occupationally exposed to lead. J Toxicol Environ Health A 75: 807-818, 2012.

66. Annunziato F, Romagnani $\mathrm{C}$ and Romagnani S: The 3 major types of innate and adaptive cell-mediated effector immunity. J Allergy Clin Immunol 135: 626-635, 2015.

67. Heo Y, Mondal TK, Gao D, Kasten-Jolly J, Kishikawa H and Lawrence DA: Posttranscriptional inhibition of interferon-gamma production by lead. Toxicol Sci 96: 92-100, 2007.

68. Dobrakowski M, Boroń M, Czuba ZP, Kasperczyk A Machoń-Grecka A and Kasperczyk S: Cytokines related to three major types of cell-mediated immunity in short- and long-term exposures to lead compounds. J Immunotoxicol 13: 770-774, 2016

69. Kamińska T, Filar J, Madej E, Szuster-Ciesielska A and Kandefer-Szerszeń M: Modification of bovine interferon and tumor necrosis factor production by lead in vivo and in vitro. Arch Immunol Ther Exp (Warsz) 46: 323-328, 1998.

70. Flohé SB, Brüggemann J, Herder C, Goebel C and Kolb H: Enhanced proinflammatory response to endotoxin after priming of macrophages with lead ions. J Leukoc Biol 71: 417-424, 2002.

71. Valentino M, Rapisarda V, Santarelli L, Bracci M, Scorcelletti M, Di Lorenzo L, Cassano F and Soleo L: Effect of lead on the levels of some immunoregulatory cytokines in occupationally exposed workers. Hum Exp Toxicol 26 $551-556,2007$.
72. Cohen MD, Yang Z and Zelikoff JT: Immunotoxicity of particulate lead: in vitro exposure alters pulmonary macrophage tumor necrosis factor production and activity. J Toxicol Environ Health 42: 377-392, 1994.

73. Liu CM, Sun YZ, Sun JM, Ma JQ and Cheng C: Protective role of quercetin against lead-induced inflammatory response in rat kidney through the ROS-mediated MAPKs and NF- $\mathrm{KB}$ pathway. Biochim Biophys Acta 1820: 1693-1703, 2012.

74. Hemdan NY, Emmrich F, Adham K, Wichmann G, Lehmann I, El-Massry A, Ghoneim H, Lehmann J and Sack U: Dose-dependent modulation of the in vitro cytokine production of human immune competent cells by lead salts. Toxicol Sci 86 : 75-83, 2005.

75. Chibowska K, Baranowska-Bosiacka I, Falkowska A, Gutowska I, Goschorska M, Chlubek D: Effect of lead $(\mathrm{Pb})$ on inflammatory processes in the brain. Int J Mol Sci 17: E2140, 2016.

76. Gao D, Kasten-Jolly J and Lawrence DA: The paradoxical effects of lead in interferon-gamma knockout $\mathrm{BALB} / \mathrm{c}$ mice. Toxicol Sci 89: 444-453, 2006.

77. Fang L, Zhao F, Shen X, Ouyang W, Liu X, Xu Y, Yu T, Jin $\mathrm{B}$, Chen $\mathrm{J}$ and Luo $\mathrm{W}$ : $\mathrm{Pb}$ exposure attenuates hypersensitivity in vivo by increasing regulatory T cells. Toxicol Appl Pharmacol 265: 272-278, 2012.

78. McCabe MJ Jr and Lawrence DA: Lead, a major environmental pollutant, is immunomodulatory by its differential effects on CD4 ${ }^{+}$T cells subsets. Toxicol Appl Pharmacol 111: 13-23, 1991.

79. Mangano K, Nicoletti A, Patti F, Donia M, Malaguarnera L, Signorelli S, Magro G, Muzio V, Greco B, Zaratin P, et al: Variable effects of cyclophosphamide in rodent models of experimental allergic encephalomyelitis. Clin Exp Immunol 159: 159-168, 2010

80. Donia M, Mangano K, Quattrocchi C, Fagone P, Signorelli S, Magro G, Sfacteria A, Bendtzen K and Nicoletti F: Specific and strain-independent effects of dexamethasone in the prevention and treatment of experimental autoimmune encephalomyelitis in rodents. Scand J Immunol 72: 396-407, 2010. 